\title{
The Gender Paradox in Public Opinion Surveys
}

\author{
ELIŠKA RENDLOVÁ* \\ Institute for Public Opinion Research, Prague
}

\begin{abstract}
The results of public opinion surveys clearly reflect real gender differences in society on questions directly pertaining to gender, but there is no fundamental difference between the opinions of men and women on other questions of civic politics or life values. This article asks whether gender is a subject which is in fact separate from other areas of life. The analysis was based on empirical material from selected data bases from 1990-1996, which included all surveys testing civic and political attitudes and values over a period of time.

In civic and political questions the only difference was the greater tendency to extreme positions on the part of men, while women tended to be noncommittal. Among the values tested, no difference was discovered between men and women. Gender as an ascribed social status modifies values directly through acquired elements of social status, a typical example of this being education.

For the values of work and social prestige the dominant influence among lower and middle education groups is age, which is reinforced by gender. Among people with higher education, the influence of age virtually disappears and gender gains in strength.
\end{abstract}

Czech Sociological Review, 1999, Vol. 7 (No. 2: 167-178)

\section{Introduction}

This article does not aim to change ideas on the current position of women from the sociological, psychological or cultural aspect, rather it is based on secondary analysis of public opinion surveys from recent years. Nor does it aim to transform empirical results into theoretical ideas, to align itself with any existing hypotheses or to formulate new ones.

I wish to focus on a paradox that constantly reoccurs: in the overwhelming majority of subjects investigated it is not possible to show any statistically significant difference in the opinions and attitudes of the two sexes. If such a difference is found it is much less than those typical of other demographic and social characteristics. From the point of view of public opinion surveys, the gender problem does not in fact exist - with one important exception. It only emerges when the subject of gender is itself the topic of research. In questions relating to the position of women, liberation or equal opportunities, the differences in the opinions of the two sexes are evident and sometimes dramatic. How can this be the case? Is the gender question an artificially constructed subject which has its own existence, set apart from all other social facts?

\section{Gender Differences and How They are Reflected in Public Opinion Surveys}

On the other hand, it is rather banal to recall the existence of real differences in the positions of men and women in society today. Empirical data show the most significant dif-

\footnotetext{
*) Direct all correspondence to: PhDr. Eliška Rendlová, Institute for Public Opinion Research,
} Sokolovská 142, 18613 Praha 8, fax +4202 6631 0404, e-mail rendlova@gw.czso.cz 
ferences in three spheres: the first is that of work, where women have been present for three generations now, but the division of the labour market into men's, women's and mixed professions still prevails. The low percentage of women in management and particularly top management is directly related to this segmentation of the labour market. Another effect of this is reflected in the economic disadvantage of the female work force (whose incomes are on average $70-75 \%$ of those of men) and in the lower social prestige of typically female professions [Čermáková 1997a]. The second area is the education system. For many subjects in secondary and higher education there is a typical differentiation in the presence of men and women, reflecting the needs of the labour market and the prestige of the profession. The third sphere is the low number of women involved in politics, particularly in high political positions and constitutional bodies.

These facts are generally known and are realistically reflected in public opinion surveys. To give one not atypical finding: the lesser opportunities for women in their careers and in management are accompanied by an awareness of the lower value of women's work and an idea of women as primarily run-of-the-mill employees with minimal decision-making powers, little authority and little opportunity to resolve common problems. Female employees are esteemed for their conscientiousness and their sensitivity in inter-personal relations [Muži... 1998]. In the political arena, there is a general sense that there are not enough women in politics and that this has a negative effect on society as a whole. The most important reasons for this are, in the public's view, family responsibilities, tradition, poor social conditions and a lack of interest among women, and the fact that the political world is a hard one [Zapojení... 1998].

Sociological research has repeatedly produced a number of findings on one further fundamental area of gender differences - the family [Čermáková 1997b and others]. In this country there is a modified patriarchal model of the family, which coexists with an unequal division of activities and a paternalistic approach to bringing up children. At the same time it is true that the ideal image of the family is much more traditional than the reality. The pre-war middle-class ideal of a one-income family where the malebreadwinner was undoubtedly dominant and the woman has a dependent position in the household, devoted to the needs of the family, is still alive and well [Rozdèlení... 1998]. This model was forcibly broken down by the communist regime at the beginning of the 1950s. That period saw the expropriation of private property, a sharp drop in salaries to the level of workers' wages and economic and political pressure for mass employment of women in unskilled professions. This pressure was accompanied by the ideological rhetoric on the liberation of women from servitude to husband, children and household and on self-realisation in work. The forced abolition of the lifestyle of the one-income family in pre-war Czechoslovakia kept this romantic patriarchal model alive and it gained new strength after the fall of the communist regime. The only area not influenced by the patriarchal ideal is sexual cohabitation, where there is in fact an idea of equal initiative by both partners.

From the point of view of the family itself, this model is considerably complicated by the need of families for two incomes, by the increasing level of education and qualifications and by their increasingly individual lifestyles. The everyday reality of the family can therefore never attain this patriarchal ideal. Married women have still been left with the largest part of traditional household responsibilities. Married men tend to be only assistants in the day-to-day division of labour, including bringing up children. In activities basically outside the family (such as earning a living, building their careers) they 
have lost their unchallenged dominance and it is probably for this reason that they have taken over the responsibility for the family budget from women. As a counter-point to women's work there has developed a now widespread model of men's doing practical and maintenance work in the household, which is to some degree a practical hobby. The Czech family therefore tends to be patriarchal in family activities, but notably liberal in decision-making powers [Ibid.]. This corresponds to the prevailing idea of the equal position of men and women in the family and with respect to the standard of living.

Alongside those areas related to work, education, politics and family life, recent years have seen the increasing predominance of another gender difference which is perceptible in public opinion: women's increasing exposure to certain social risks. The most serious of these are sexual harassment and domestic violence, together with unemployment. General crime, health risks and stress, on the other hand, are seen as an equal danger for both sexes [Rovnost... 1999].

Despite these facts and their clear reflection in public opinion surveys, the subject of gender differences is greeted with some embarrassment. This is evident in journalism, in political debate and in statements by prominent individuals. The most pronounced distaste is directed towards women's liberation or the feminist movement. Women tend to keep quiet on the subject while men play it down or satirise it. This may partly be due to the political and economic misuse of women's liberation to suit the needs of the communist political system and the renaissance of the traditional paternalistic ideal of the family, but this alone cannot entirely explain it.

\section{Are there Separate Men's and Women's Worlds?}

Is it possible to talk of the different realities of men's and women's lives? Literature, journalism and even gender and feminist discussion constantly put forward the idea of separate worlds of men and women, which can only meet with difficulty [OatesIndruchová 1999]. If the problem is considered purely from the aspect of gender differences then the reply to this question is clear - there are differences and these are reflected in the different worlds. Does this, however, also apply to other social phenomena? If there are more or less separate men's and women's worlds, it should be possible to identify them in the structure of attitudes and values which are not directly related to questions of gender.

As an empirical basis for verifying gender differences in ideas on the broader spectrum of life in society, I have taken the results of surveys by the Institute for Public Opinion Surveys between 1990 and 1997. The surveys were carried out on population samples selected on a quota basis, the size of the samples ranging between 800-1200 respondents over the age of 15 . The samples are representative as the quota signs are age, sex, education, region and size of settlement. For this analysis specific data samples were created which included all surveys dealing with these areas between 1990 and 1997.

\section{Tendency to Neutrality in Women's Civil and Political Attitudes}

The first area considered was civil and political attitudes, which were tested by a repeated set of questions. These dealt specifically with satisfaction with the present social development and expectations for the immediate future, and with trust in public institutions, the importance of social problems and an assessment of the government's ability to resolve them. In all cases the respondents gave their answers on the four-point scale of $1=$ definitely yes, 2 = probably yes, 3 = probably not, and $4=$ definitely not. They could also 
choose a fifth possibility of "don't know". For more complex political attitudes the analysis included respondents' own placement of themselves on a left-right axis using a sevenpoint scale [Občanské... 1991-1997].

A comparison of the averages for these questions did not show any statistically significant gender differences. This is valid for all indicators without exception, whether trust in public institutions, satisfaction with the overall development, assessment of individual aspects, or self-placement on the left-right axis. A high level of agreement in the attitudes of men and women was found throughout the period studied. Since no differences were found in the judgements on individual points, the overall character of the response was also analysed. Here there was a statistically significant gender difference, in women's tendency to opt for the neutral "don't know" answer, and a greater liking for the extreme positions (positive or negative) on the part of men. This tendency is evident throughout the structure of civil and political attitudes, regardless of their actual content, and throughout the period under consideration.

There is no clear interpretation of the greater distance adopted by women. The simplest hypotheses is that women generally place less importance on civil and political subjects, but this is improbable since it would suppose at least some differences depending on the concrete question. The distance was, however, found in all social matters, many of which have a direct impact on everyday life (e.g. standard of living, salary policies, social security, health care, crime, etc.) and have a major influence on the lives of all individuals. The explanation may rather be found in the gender-specific styles of communication. The model of male dominance corresponds more to decisive, extreme statements, while female submission is more likely to be linked with gentler formulations. If this hypothesis is true, it still does not tell us whether the basis of the different ways of behaving is primarily cultural or primarily psychological. For a more searching examination of these questions, sociology must align itself with ethnological and psychological research and indeed with other disciplines too.

\section{Conformity between Men's and Women's Values}

The second group of data analysed concern value orientations. These were surveyed each year using a set of partial statements which were placed on a four-point scale of importance, ranging from $1=$ very important to $4=$ not important at all, again with an option 5 = "don't know". This time there was no greater neutrality on the part of women (as judged by the frequency of "don't know" responses) nor any inclination towards the extreme responses on the part of men. The "don't know" responses were excluded from further processing [Životni... 1990-1997]. 
Table 1. The Importance of Life Values - Means and Standard deviations (Surveys from 1990 and 1997)

\begin{tabular}{|c|c|c|c|c|}
\hline \multirow[b]{2}{*}{ Value } & \multicolumn{2}{|c|}{1990} & \multicolumn{2}{|c|}{1997} \\
\hline & Mean & S. D. & Mean & S. D. \\
\hline living in a happy family & 1.15 & 0.42 & 1.14 & 0.42 \\
\hline living in healthy environment & 1.20 & 0.48 & 1.38 & 0.61 \\
\hline being healthy and looking after my health & 1.31 & 0.56 & 1.43 & 0.64 \\
\hline helping mostly my friends and family & 1.35 & 0.55 & 1.31 & 0.54 \\
\hline having true friends & 1.36 & 0.56 & 1.36 & 0.57 \\
\hline living in a beautiful place & 1.36 & 0.56 & 1.47 & 0.63 \\
\hline living according to my personal convictions & 1.39 & 0.61 & 1.45 & 0.64 \\
\hline having interesting work which I enjoy & 1.43 & 0.75 & 1.59 & 0.90 \\
\hline having valuable and useful work & 1.44 & 0.73 & 1.59 & 0.85 \\
\hline working with pleasant people & 1.57 & 0.82 & 1.82 & 0.94 \\
\hline helping anyone who needs help & 1.72 & 0.72 & 1.92 & 0.78 \\
\hline doing my job well & 1.77 & 0.92 & 2.01 & 0.97 \\
\hline earning a lot of money & 1.80 & 0.89 & 1.93 & 0.95 \\
\hline preserving my privacy & 1.80 & 0.84 & 1.82 & 0.80 \\
\hline \multicolumn{5}{|l|}{ being well-informed about events here } \\
\hline and in the world & 1.81 & 0.76 & 2.10 & 0.84 \\
\hline being well-liked & 1.87 & 0.79 & 1.95 & 0.80 \\
\hline \multicolumn{5}{|l|}{ having a broad general knowledge, a general idea } \\
\hline of culture, science, technology and politics & 2.03 & 0.90 & 2.09 & 0.87 \\
\hline having friends who may be useful & 2.07 & 0.88 & 2.17 & 0.88 \\
\hline helping build democracy in society & 2.07 & 0.89 & 2.39 & 0.89 \\
\hline living well and enjoying life & 2.12 & 0.89 & 2.15 & 0.89 \\
\hline helping to improve life in the place where I live & 2.13 & 0.83 & 2.42 & 0.84 \\
\hline having time for my hobbies and interests & 2.19 & 0.88 & 2.10 & 0.79 \\
\hline \multicolumn{5}{|l|}{ having a job just to be employed } \\
\hline and not need state benefits & 2.23 & 1.08 & 2.49 & 1.09 \\
\hline helping mostly those who appreciate the help & 2.25 & 0.90 & 2.31 & 0.88 \\
\hline having work which lets me try new things & 2.26 & 1.01 & 2.40 & 1.01 \\
\hline having an interesting and exciting life & 2.36 & 0.97 & 2.46 & 0.95 \\
\hline having nice things which not everyone has & 2.71 & 0.96 & 2.85 & 0.93 \\
\hline achieving an important position in society & 2.77 & 0.97 & 2.83 & 0.94 \\
\hline \multicolumn{5}{|l|}{ having a job which lets me control the activities } \\
\hline of other people & 2.94 & 0.97 & 2.97 & 0.94 \\
\hline having my own company where I can be my own boss & s 2.96 & 1.06 & 2.96 & 1.07 \\
\hline promoting the policies of my party or movement & 2.97 & 1.01 & 3.13 & 0.96 \\
\hline living according to my religion & 2.98 & 1.10 & 3.09 & 1.03 \\
\hline
\end{tabular}

Evaluation on the scale 1 = very important, 2 = quite important, $3=$ not very important, $4=$ not important at all, and $5=$ don't know (the "don't know" responses were excluded from the calculation).

As Table 1 shows, values tend to be very stable. Their order of importance did not change greatly between 1990 and 1997, even though society developed rapidly during this period. The most important set of values express social-biological roots, including family, health, and family or informal social networks, which are partly dependent on a certain material and aesthetic standard. A second fundamental value is the intellectual dimension and only then follows the broader social context. This is represented by a complex char- 
acteristic of work as the most important economic and social link between the microsphere and the broader social environment. Less importance is placed on education and informedness, and civil and political involvement and religious confession come close to the bottom of the scale.

Table 2. Results of the Factor Analysis of the Entire Sample

\begin{tabular}{ll} 
& factor loadings \\
\hline lst factor - Work & \\
having interesting work which I enjoy & 0.78 \\
having valuable and useful work & 0.76 \\
working with pleasant people & 0.72 \\
doing my job well & 0.65 \\
having a job, just to be employed and not need state benefits & 0.62 \\
earning a lot of money & 0.59 \\
having work which lets me try new things & 0.50 \\
2nd factor - Social Prestige & \\
achieving an important position in society & 0.71 \\
having a job which lets me control the activities of other people & 0.68 \\
having my own company where I can be my own boss & 0.67 \\
having an interesting and exciting life & 0.53 \\
having nice things which not everyone has & 0.50 \\
having friends who may be useful & 0.44 \\
living well and enjoying life & 0.40 \\
being well-liked & 0.36 \\
earning a lot of money & 0.35 \\
3rd factor - Democracy & \\
helping build democracy in society & 0.73 \\
being well-informed about events here and in the world & 0.68 \\
helping to improve life in the place where I live & 0.61 \\
promoting the policies of my party or movement & 0.61 \\
having a broad general knowledge, a general idea of culture, science, & \\
technology and politics & 0.60 \\
helping anyone who needs help & 0.41 \\
4th factor - Social-Biological Roots & \\
living in healthy environment & 0.65 \\
living in a beautiful place & 0.62 \\
being healthy and looking after my health & 0.62 \\
having true friends & 0.54 \\
living in a happy family & 0.48 \\
helping mostly my friends and family & 0.48 \\
living according to my personal convictions & 0.41 \\
being well-liked & 0.39 \\
5th factor - Creativity & \\
having time for my hobbies and interests & 0.68 \\
preserving my privacy & 0.66 \\
living well and enjoying life & 0.64 \\
having nice things which not everyone has & 0.45 \\
having an interesting and exciting life & 0.43 \\
& \\
& \\
&
\end{tabular}




\begin{tabular}{lc} 
& factor loadings \\
\hline 6th factor-Christian Solidarity & \\
helping mostly those who appreciate the help & 0.55 \\
living according to my religion & 0.48 \\
having friends who may be useful & 0.42 \\
helping anyone who needs help & 0.39 \\
having a job just to be employed and not need state benefits & 0.37 \\
\hline
\end{tabular}

Main component method, Varimax rotation, Rotated factor matrix $\mathrm{N}=7757$

Factor analysis isolated the six most important factors. The first of these is undoubtedly work, which is valued primarily as an opportunity to be creative, to do something of benefit to society and to be professional, and to have good interpersonal relations. The aspects of financial necessity and security are less important, as is that of innovation.

The second factor concerns the wider spectrum of values which can be interpreted as social prestige. This is linked primarily with an important position in society and work as a manager or private entrepreneur. This factor is however a complex one. It also includes material comforts and being well-rooted in a social network, which in fact contribute to achieving an aim and are an informal confirmation of social prestige. The entire complex of these values is rounded out by the idea of an interesting and exciting life.

The third factor expresses the value of democracy, and its most important element is that of activity and information. A dominant role is given to involvement in the societywide process of democratisation, which includes activity in different areas of society, such as parties and local government, and in informal civic solidarity. The second part of this factor is the value placed on democratic freedom of information, either as day-to-day contact with domestic and international affairs or as a required standard of education which will ensure a broad general knowledge and an overview of areas of individual interest.

The fourth factor is again a broad spectrum of values which as a whole express people's need for social-biological roots in the world today. The natural conditions judged from the point of view of health and aesthetic qualities are combined with the needed stability in the intimate social sphere composed of the family and informal interpersonal relations. Here equal value is placed on mutual effectiveness and emotional support, in combination with inner personal values expressed by the need "to live the way I want to".

The fifth factor can be termed spare-time creativity and is to some degree complementary to creativity at work, which was included in the first factor. The dominant elements are interests linked with a person's private life, well-being and material comfort. This factor is also linked with an idea of an interesting and exciting life, which (unlike the other characteristics of the social prestige factor) is tied to individual interests and undisturbed privacy.

The sixth factor expresses Christian solidarity, in which the most important elements are mutual support in the context of religious belief. Solidarity is linked with the idea of work as a source of livelihood and a rejection of state social benefits.

The correlation of factor scores with social demographic characteristics of the relevant age, sex and education confirm a certain link between the three strongest factors, which define the person's relation with society through the value placed on work, social 
prestige and democratic society. The factors of work (0.41) and social prestige (0.30) are linked with the age structure, while the democracy factor is rather more loosely tied to the level of education (0.24). No differences according to gender were found. The structure of values in the population is therefore basically the same for men and women and it cannot be said that there are separate men's and women's worlds. We are back to being common parts of a single world.

This fact was confirmed by separate factor analyses for the samples of men and women.

Table 3. Differing Factors in the Sample of Women

\begin{tabular}{lc} 
& factor loadings \\
\hline Democracy & \\
helping build democracy in society & 0.74 \\
helping to improve life in the place where I live & 0.67 \\
being well-informed about events here and in the world & 0.65 \\
promoting the policies of my party or movement & 0.63 \\
helping anyone who needs help & 0.51 \\
having a broad general knowledge, a general idea of culture, & \\
$\quad$ science, technology and politics & 0.50 \\
Christian Solidarity & \\
helping mostly those who appreciate the help & 0.60 \\
having friends who may be useful & 0.54 \\
living according to my religion & 0.37 \\
having a job just to be employed and not need state benefits & 0.36 \\
having a broad general knowledge, a general idea of culture, & \\
$\quad$ science, technology and politics & 0.35
\end{tabular}

There is little difference in the delineation of the factors for the male and female population, with one exception, i.e. the differing way in which education and informedness are understood. Women see these instrumentally, as an element, context or means of social relations, and they are present in two factors. These are the complex of democratic values, where they are linked with participation and activity on the local and society-wide levels, and Christian solidarity, where they are linked with living according to religious precepts and function as an element of a certain type of social network.

Table 4. Differing Factors in the Sample of Men

factor loadings

Civic-Christian Solidarity

helping to improve life in the place where I live 0.65

promoting the policies of my party or movement $\quad 0.60$

helping anyone who needs help $\quad 0.57$

helping build democracy in society $\quad 0.56$

living according to my religion $\quad 0.50$

helping mostly those who appreciate the help $\quad 0.44$ 


\begin{tabular}{lc} 
& factor loadings \\
\hline $\begin{array}{l}\text { Education and Spiritual Dimension } \\
\text { being well-informed about events here and in the world }\end{array}$ & 0.67 \\
having a broad general knowledge, a general idea of culture, & \\
$\quad$ science, technology and politics & 0.66 \\
helping build democracy in society & 0.49 \\
living according to my personal convictions & 0.36
\end{tabular}

For men the values of education and informedness have a different significance. They form an independent fifth factor, which can be defined as the educational and intellectual dimension, since it also includes the desire to "live according to my personal convictions". As far as the use of information is concerned, men place it on the society-wide level of "helping to build democracy in society". The more concrete form of local or party politics or human solidarity becomes part of the fourth factor described as civicChristian solidarity.

\section{The Mediatory Influence of Gender}

With the exception of the differences noted above, the factors obtained from the separate samples of men and women confirm the high degree of similarity. Therefore, no direct influence of gender on the value structure was demonstrated. The question remains as to whether values are really so immune to the influence of gender or whether this influence operates in a less obvious way. Gender as an ascribed social status can modify values indirectly through the social status acquired. A typical example of this is education. To test this hypothesis we analysed the given value groups in three educational groups. Within these groups we tested the influence of gender and age (generation) in the form of dichotomic categories. Since the effect of age manifested itself mainly in the different social situation of employed people and pensioners, the sample was limited to those under 50. The dichotomy of generations was set with the age groups of $15-35$ and $36-50$ years.

Table 5. Calculated Correlation between the Discriminatory Functions and Variables Included in the Analysis of Discrimination (by level of education, gender and generation*)

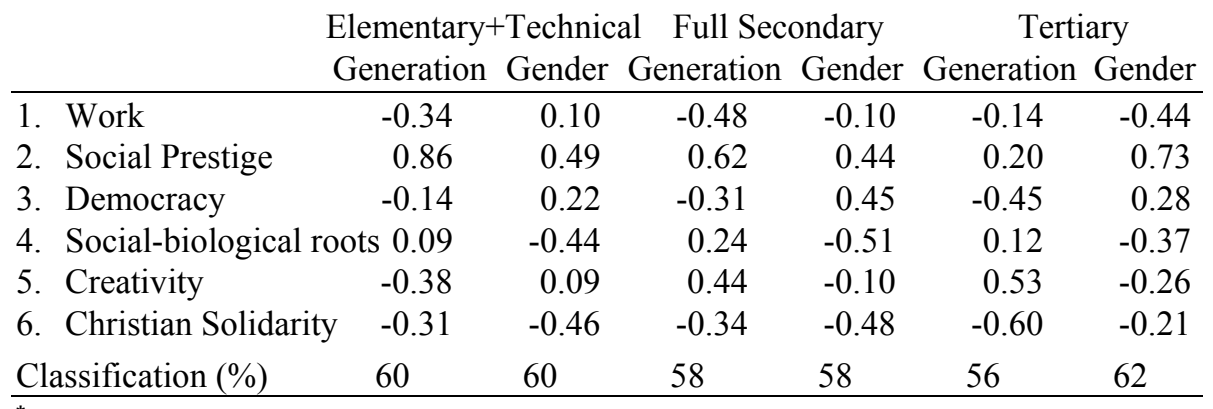

*) Generations were set as 15-35 years and 36-50 years.

The influence of age and gender appears separately, even in individual factors within educational groups. The first two factors are subjectively the most significant and express the individual's existential and social roots in society. In general, for these factors the dominant principle in lower educational groups is that of seniority, while among those with university education it is gender. 
In concrete terms this means that in the factor of work for the lower and middle educational groups, age is the most important and the influence of gender is insignificant. In the university-educated group the situation was virtually reversed - the basic criterion of differentiation is gender and age is not significant. The social prestige factor is generally very dependent on demographic characteristics. In the lower categories the influence of age is the strongest, and in the middle one this is joined with gender. In actual life this means that among people with elementary or technical education a mature man has a high chance of having high social prestige and a young woman a very low one. In the middle group the influence of age is slightly weaker but still dominant, while the influence of gender is fairly strong. Among university-educated people this dependence is reversed. There, age is unimportant for social prestige, but gender is very strong. It is as if it has absorbed part of the social significance of the age difference and become the bearer of the overall influence of the demographic structure on values. This shows that the feminist movement and gender studies are reacting to a real and very strongly felt problem of discrimination by sex, which is experienced by educated women. In other social strata this fact is not felt so strongly, since it is masked by the principle of seniority, which is more dominant the lower the social stratum.

The Christian solidarity factor is something of a counter-point. While it is subjectively the least important, it, like the previous two factors, expresses a certain type of relationship between the individual and society, which has a long historical development and a basically spiritual dimension. In this factor the principle of seniority works somewhat differently. While in the lower and middle educational groups, age and gender have more or less the same degree of influence, among university-educated people age becomes dominant and the influence of gender declines. The sharing of humanitarian values is clearly not an obvious feature of all strata of modern society. The formerly important educational role of the church has not been taken up by either the family or elementary schooling. The importance of humanitarian values in people's lives manifests itself gradually, together with a broader educational base and rich life experience.

The factor of social-biological roots, which basically incorporates the microsphere including family and kinship structures, is differentiated by gender in all educational groups. Its influence is somewhat stronger in the middle group and lowest among the university-educated group, but the differences are not great. The influence of age was negligible. This can be said to be an area where the different status of men and women is reflected in all educational groups.

In each of the remaining two factors the influence of age and of gender acted differently. There was a relatively clear differentiation in the value of creativity, in which life experience is clearly valued and increasingly so with rising education. This factor can also act as a counterpoint for the factor of social-biological roots. There is greater pressure of time and interest exerted by families with dependent children, which weighs more on women. With rising age both partners gain greater space for their own interests.

The democracy factor shows relatively little importance for the lowest educational group, where the demographic characteristic did not appear at all. For high school and university graduates, the influence of age and gender is virtually the same. 


\section{Conclusion}

The analysis of public opinion surveys from the point of view of gender differences revealed that this is a complex problem. In terms of a simple relation between gender and opinion, a link was found only in those subjects which directly concern gender issues. For other subjects the direct influence was minimal. However, if gender is analysed as a contextual variable, acting through other social characteristics, such differences can be shown to exist, and can be quite striking. In this article two such findings were described:

In attitudes to civil values the influence of gender appears not in the actual value placed on different subjects but in the overall style of evaluation. Among men there is a tendency to extreme opinions (positive and negative), while among women there is a tendency to neutrality, represented by the more frequent "don't know" responses. This finding does not apply to value orientations.

In the area of values, gender differences do not manifest themselves directly but through status, and the same is true for generational differences. For the most important social ties - work and social prestige - the gender differences are stronger in the university-educated group, where the influence of generation is unimportant. In the lowest educational group, on the other hand, generational influence is dominant and is reinforced by gender to differing degrees.

The difference function of gender and generational influence in relation to education may be linked to a certain rejection of gender questions in public opinion. This is a subject most discussed among educated women and in lower educational groups it may not arouse sufficient interest. The data show that there is a stronger link between lower education and a sense of generational differences, which the university-educated population does not greatly feel. The fact that the subject of generational inequalities has not received much interest among the public, may be linked with the dominance of university-educated professionals in the intellectual, journalistic and political elite. Lower educational groups may make less use of these possibilities for expressing their opinions, or have little opportunity to make their voices heard through the media. The importance of the generational conflict may not be considered at all by society for a long time. And if there are indeed such tensions, women in non-white-collar jobs may see the gender question as unimportant or foreign to them.

The tendencies extrapolated from the data analysed may become stronger in the future. The continuing rise in the level of education and the increasing number of people with a university education may mean that the importance of gender differences will be felt more and more strongly. This is clearly a subject which is only just appearing in the new political and socio-economic conditions in Czech society. Social tensions arising from both gender and age differences may intensify due to the fact that they have until now been overlooked by the political elite.

ELIŠKA RENDLOVÁ studied at Charles University in Prague. She worked in the Institute of Sociology of Academy of Sciences of the Czech Republic and in the Law Faculty of Charles University. Her main area of interest is questions of the family, young people and age groups. Since 1994 she has been Director of the Institute for Public Opinion Research in Prague.

\section{References}

Čermáková, M. 1997a. "Postavení žen na trhu práce" [Women in the Labour Market]. Sociologický časopis 33: 389-404. 
Čermáková, M. 1997b. Rodina a měnicí se gender role - sociální analýza české rodiny [The Family and Changing Gender Roles - A Social Analysis of the Czech Family]. Working Papers 97:8. Praha: Sociologický ústav AV ČR.

Muži a ženy v rídicich funkcich [Men and Women in Management Roles]. 1998. (IVVM press release, 3. 9. 1998). Praha: IVVM.

Oates-Indruchová, L. (ed.) 1999. Dívčí válka s ideologií [The Maid's War with Ideology]. Praha: SLON.

Občanské postoje [Civic Attitudes] 1991-1991. (IVVM data samples). Praha: IVVM.

Rovnost mužů a žen [Equality of Men and Women]. 1999. (IVVM press release, 11. 5. 1999). Praha: IVVM.

Rozdělení činností včeské rodině [Division of Work in the Czech Family]. 1998. (IVVM press release, 4. 9. 1998). Praha: IVVM.

Zapojení žen do politických funkcí [Women's Inclusion in Political Functions]. 1998. (IVVM press release, 20. 5. 1998). Praha: IVVM.

Životni hodnoty [Life Values]. 1990-1997. (IVVM data samples). Praha: IVVM. 